\title{
When geophyics meet geochemical reactive transport in a tropical volcanic critical zone
}

\author{
SYLVAIN PASQUET ${ }^{1}$, NICOLE M. FERNANDEZ ${ }^{2}$, \\ JORDEN L. HAYES ${ }^{3}$, LIN MA ${ }^{4}$, PETER SAK ${ }^{3}$ AND JÉRÔME \\ GAILLARDET $^{1}$ \\ ${ }^{1}$ Institut de physique du globe de Paris \\ ${ }^{2}$ Cornell University \\ ${ }^{3}$ Dickinson College \\ ${ }^{4}$ University of Texas et El Paso \\ Presenting Author: n.fernandez@cornell.edu
}

Many life-sustaining features of Earth's terrestrial system are supported by weathering in the deep Critical Zone (CZ), e.g., nutrient supply, groundwater flow, and regulation of atmospheric $\mathrm{CO}_{2}$. Consumption of $\mathrm{CO}_{2}$ by rock weathering is usually intense in basaltic islands with tropical climates, where increased temperature and precipitation accelerate chemical reactions. In the Lesser Antilles, strong precipitation gradients between windward (WW) and leeward (LW) watersheds lead to firstorder differences in chemical weathering. These differences are thought to produce distinct weathered profiles at depth. Yet, such assumptions remain difficult to validate because of the hidden nature of the deep CZ. To capture these distinctions between catchments we conducted geophysical surveys on Basse Terre island (Guadeloupe, France), which is characterized by strong differences in mean annual precipitation (MAP) between LW and WW sides and a lithology comprised of successive lava flows of similar andesitic composition with different ages. We collected seismic refraction data at three sites on the island spanning MAPs between 1.6 and $5.0 \mathrm{~m} / \mathrm{yr}$ and ages between 1.8 and 0.6 Ma from LW to WW sides. Seismic surveys were performed on prominent relict surfaces of the island and above knickpoints in order to assume similar erosion rates between sites. All surveys show thick weathered profiles with bedrock depth $>40 \mathrm{~m}$. However, LW surveys show thicker $(\sim 25 \mathrm{~m})$ lowvelocity material $(<1.2 \mathrm{~km} / \mathrm{s})$ with weak velocity gradients near the surface and sharp strong velocity gradients at depth. In contrast, WW side surveys are characterized by relatively homogeneous velocity gradients with depth and thinner $(<15 \mathrm{~m})$ low-velocity regions. These results suggest that WW and LW catchments have significantly different weathering profiles, highlighting the contrasted impact of combined precipitation and time over chemical weathering. In order to validate these assumptions, we performed reactive transport modeling at the 3 sites using local MAP and age, with mineral composition and dissolution kinetic constants calibrated from previous works conducted on the weathering of volcanic clasts in Guadeloupe. This study shows a good agreement between the geophysical and geochemical interpretations showing that nondestructive geophysics in tropical islands can inform long term interactions between atmospheric carbon and rocks. 